\title{
SUSTAINABLE INFORMATION TECHNOLOGY TRANSFORMATION TO MODERN RAILWAY SERVICES
}

\author{
Indriyati ${ }^{1}$, Sarinah Sihombing ${ }^{2}$, Otong Sunaryo ${ }^{3}$, Nita Rosmala Dewi ${ }^{4}$ \\ 1. STMT Trisakti, 2. STMT Trisakti, 3. STMT Trisakti, 4. STMT Trisakti \\ $\triangle$ corresponding author: indry_in@yahoo.com
}

\begin{abstract}
PT Kereta Api Indonesia (KAI) has been continuously transforming its services in the past eight years. Since 2009, PT KAI has improved its quality and service to rail transport users. PT KAI has been modernizing the bidding system, making KAI Access applications, rejuvenating facilities, improving infrastructure and service facilities throughout the station, to establish Contact Center 121 service. PT KAI also made several innovations in order to provide the best service, such as making Rail Clinic, e-boarding pass, ticket vending machine, cashless transaction. The transformation led PT KAI to produce good results. Over the past five years, passenger volume growth increased on average by $13.2 \%$ and revenue growth by 19\%. In 2017, PT KAI is expected to carry up to 374 million passengers. Transformation in information system and technology used by PT KAI has shown profit nowadays. Descriptive exploratory analysis method was used to answer the problems among what had been done by PT KAI in doing the transformation in it. Keywords : information technology, innovation, modern service
\end{abstract}

\section{Introduction}

The management of PT KAI stated that the reform of information technology conducted by new management since 2009 aims to support the business transformation process in line with the vision and mission of the new PT KAI. The use of information technology as a process of transformation is not something new, although the mechanisms and outcomes can vary from one company to another. The use of information technology will help companies to improve the quality of service to customers, with better service expected by the company to be more efficient and ultimately have higher competitiveness. Although PT KAI is not a fully commercial company, service is an important and even crucial aspect of a railway company. As time passes, technology development increasing in PT KAI makes passengers easier switch the transportation from using bus as public transport or private cars to railway transport services to many passenger's destinations. Thus, it increases the number of users of rail transportation services. However, the number of demands and consumer complaints against the Railway both for 
consumer convenience and service and for facilities provided by PT KAI are still not satisfying. With the many demands of the consumer, the company begins to make some changes in accordance with the demands of consumers, including improvement to consumer facilities, curbing street vendors in the train, and so on that concern about consumer convenience. In the process of changing which doesn't always run well, sometimes there are some obstacles.

The obstacles are both from internal parties such as employees who are unable to adjust to the existing changes and external barriers such as consumers who don't know and understand the new changes made by companies. This will confuse the consumer because of the lack of corporate socialization. Based on the description above, we try to decipher it in this paper about how the change of management in PT KAI is seen from the point of view of the students as a neutral academic against the existing phenomenon. The change in financial, corporate management, organizational chart, including performance and culture of all employees is very important for PT KAI bbecause basically PT KAI is one of State Owned Enterprises (BUMN); consequently, the mindset of employees still think that some employees consider themselves as government employees. After the change, the employees no longer think of the bureaucracycy but they start to think of being entrepreneur. (Kadarisman, Gunawan, \& Ismiyati, 2016) connection of land transportation with the economy of society.

It means that when employees still think of bureaucracycy, they will ask themselves to be served or give less attention to the consumer, while when employees think as entrepreneur, they will implement a proactive system which means the consumer is the main priority of service company. Thus, when there is a mistake in the company's service, such as poor service and inadequate infrastructure service, the employee will be punished by the company. Different from what happened in the past, the regulation was not applicable. They ignored the complaints reported by consumers because they assumed that the company belonged to the government. So all the complaints reported by consumers to the government had no response. In this case, the 
mindset of employees as entrepreneur, is the basic thing of the company to make a good change. (Saribanon et al., 2016) given quality impact on consumer satisfaction.

Obstacles to Change Process in PT KAI

In the process of changing in PT KAI, there is a conflict between internal party and external party.

\section{Internal party}

Internal parties are people who are within the organization or companies that deal directly with the organization or company. Internal parties in PT KAI are some employees of the company who do rejection of changing process, because they think the changes will affect them, not only impact of the level of difficulty of work, but also time pressure on task performance, and others. The time of change is relatively fast, so that employees cannot afford or cannot keep up with changes that have been set by the leader. Some employees that cannot keep up with the changes consequently are eliminated by early retirement or even fired by the company if the employees hamper the changes. The dismissal, of course, is proportionally done when they are eligible for being dismissed or fired because of poor performance.

2. External parties

External parties are people outside the organization. External parties are citizen, community and public that don't know enough about the company's changing, so the company takes a long time to socialize to the community about the changes made by PT KAI.

Based on the descriptions above, we try to find out how the change management in PT KAI is seen from an academic point of view as a neutral academic against the existing phenomenon.

The issues to be discussed in this paper are:

1. How is the process of change made by PT KAI in improving the quality of service to consumers? 
2. What obstacles are faced by PT KAI in improving the quality of service to consumers?

3. What is the effect of changes made by PT KAI in improving the quality of service to consumers?

The purposes of this paper are:

1. Knowing the process of change made by PT KAI in improving the quality of service to consumers?

2. Knowing what obstacles are felt by PT KAI in improving the quality of service to consumers?

3. Knowing the effect of changes made by PT KAI in improving the quality of service to consumers?

For PT KAI, it is very important to meet customer demand and need. PT KAI must satisfy not only the customer, but also the company's interest. If the company can fulfil the demand quickly then the customer will be more satisfied and on the other side the company can accelerate its money needed to fund routine activities and company's development. Therefore, customer service and complaint handling accompanied by the standard of service must be continuously improved. The standard services including the quality of the system and human resources, the target of increasing the frequency of capacity increase, the addition of the number of lines and the KAI route will increase the number of customers to be served by PT KAI.

(Tsai, 2014) Organizational climate indicated that the daily behavior of interaction within the organization. Mc Gregor (1960) argued that the climate is primarily determined by the managerial assumptions and the relationship between the managers and their subordinates. (Ralph et al., 1995) The nature and economic costs of congestion to eight different groups (airlines, airports, air, travelers, tourist industry, labor pool, business and industry, governments and aircraft manufacturers) are identified, and the penalties of inadequate infra- structure are outlined.

(Durugbo, Tiwari, \& Alcock, 2014) Fundamentally, delivery reliability by firms and supply chains is dependent on information for two main reasons: 
first, information serves as an input for formulating delivery process strategies and second, information acts as a control measure for achieving high levels of delivery times. (Koo, Chung, \& Kim, 2015) Smartphones are one of the latest developments in mobile computing technology. Smartphone is an emerging phenomenon for personal and business voice, data, e-mail, and social networking communications, as well as having applications.

(Ngee Goh, 2014) In the face of this transition, it may be noted that education and training programs for quality today are often built on the wisdom of past quality gurus. However, past teaching was mostly oriented toward generation of goods rather than services. With increasing emphasis on quality of service today throughout the world, the traditional pedagogical approach needs not just an adjustment or extension, but a fundamental paradigm shift. (Satapathy, 2014) Service industries have become very competitive and customers are more concerned about quality today. Nowadays, customers are very choosy about how they spend money. Quality products or services are their first and foremost preferences. For a service provider, the challenge is to enhance their service and emphasize its desirability so that customers' expectations are met.

(STMT Trisakti, Indah Susanthi STMT Trisakti, Setiawan STMT Trisakti, Indah Susanthi, \& Dian Octaviani, 2014) leadership style has an effect on management. (Juliater Simarmata, Charles, \& Rizaldy, 2014) exchange rate increase against industrial sustainability. (Ismiyati, Firdaus, \& Arubusman, 2016) Maintenance management to achieve service standards.

\section{Method}

This research used descriptive exploratory method. The methods used are semi-structured interviews and structured interviews with active involvement of researchers in Participatory Ethnobotanical Appraisal (PEA) activities (Rugayah, et al., 2004).

The population in this study is people who use Railway transportation, 80 respondents from the population of 100 respondents with 5\% error factor that directly impact on carrying out daily activities of passengers. So the 
transformation conducted by PT KAI especially in information technology improves the quality of service to become more modern and sustainable services.

Variable Research, based on the above understanding, then in this study there is one variable, namely Information Technology Transformation PT $\mathrm{KAI}$ in general.

Instrument Research, tools used in this research are digital camera, stationery writing, recorder (tape recorder) and interview question.

A preliminary study was conducted to determine the initial situation in the field and IT readiness in PT KAI in operational and service quality readiness. A survey was conducted directly to PT KAI and infrastructure and operational services. At this stage an open interview is conducted to the public. According to Patton Poerwandari (1998) in the interview process using general guidelines, interviews are equipped with very general interview guidelines, and include issues that should be covered without specifying the order of questions, and may not even form explicit questions.

A survey is conducted directly to public or citizen as train users. An open interview is about infrastructure and operational services of PT KAI based on a list of questions that has been prepared by researchers, then the researchers will take picture and record data. According to Patton Poerwandari (1998) in the interview process using general guidelines, interviews are equipped with very general interview guidelines, and include issues that should be covered without specifying the order of questions, and may not even form explicit questions.

Data analysis by Patton (Poerwandari, 2013, p.183) is the process of organizing the sequence of data organizing into a sequence of category pattern and a basic sequence. Based on the views of Bodgan and Taylor as quoted by Moleong Lexy they define data analysis as a process that explains detail effort formally to find the theme and formulate a working hypothesis as suggested by the data or an attempt to provide assistance from themes and hypotheses. Data obtained, then are written as a draft concept used as the main basis in providing data. For analyzing data, this study uses descriptive 
analysis (non statistic), so this research describes data obtained from respondents' words and sentences which are separated in many areas to draw a conclusion. In general, these are the stages of data analysis process:

Researchers use data reduction for selecting process, focusing, simplification, abuses and transparency of rough data arising from field notes. Therefore the step undertaken by the researchers is to summarize the data by selecting important data and then simplify data. In this data reduction, the researchers perform the process of selecting data and eliminate waste data either from the observation, interview or documentation. This data reduction is done continuously, from the beginning to the end of data collection activities in the field, even until the writing of the final report is composed completely. Therefore, by reducing data, the study will provide a sharper picture of the observed results and it will also be easier for researchers to retrieve the data needed.

Researchers use display data for the process of organizing the data so that it is easily analyzed and concluded. Presentation of data in this research is a form of description and narration combined with images, scheme, matrix, table, formula, and others. This is adapted from the type of data collected in the data collection process, either from respondents' observation, in-depth interviews, or documentation studies. In other words, the process of presenting this data is a process of arranging information systematically in order to obtain conclusions as research findings. In this study, data obtained by researchers present in the form of textual descriptions that are narrative in accordance with the characteristics and patterns of this research which is qualitative research. Therefore, to be able to take action and withdraw the right conclusions, the researchers must make the presentation of data by combining the all information arranged in an organized form to be more easily understood.

Researchers use data verification as the third step in the analysis process. The conclusions are at first very tentative, vague, and doubtful, then with increasing data they become more substantial. This activity is the process of checking and testing the truth of the data that has been collected 
so that the final conclusion is obtained in accordance with the research focus. The initial conclusion that has been formulated is checked again (verification) on the note that has been made by the researcher and then headed toward the steady conclusion. The conclusion is the essence of the results of research that describes the last opinion of the researcher. The final conclusion is expected to have relevance to the focus of research and answer the problems of the research that have been formulated previously. Then the data collected are interpreted and concluded so that the various problems that arise can be described precisely and clearly. The process of data analysis conducted by Miles and Huberman is data collection, data reduction, data presentation and conclusion. In detail the steps are as follows:

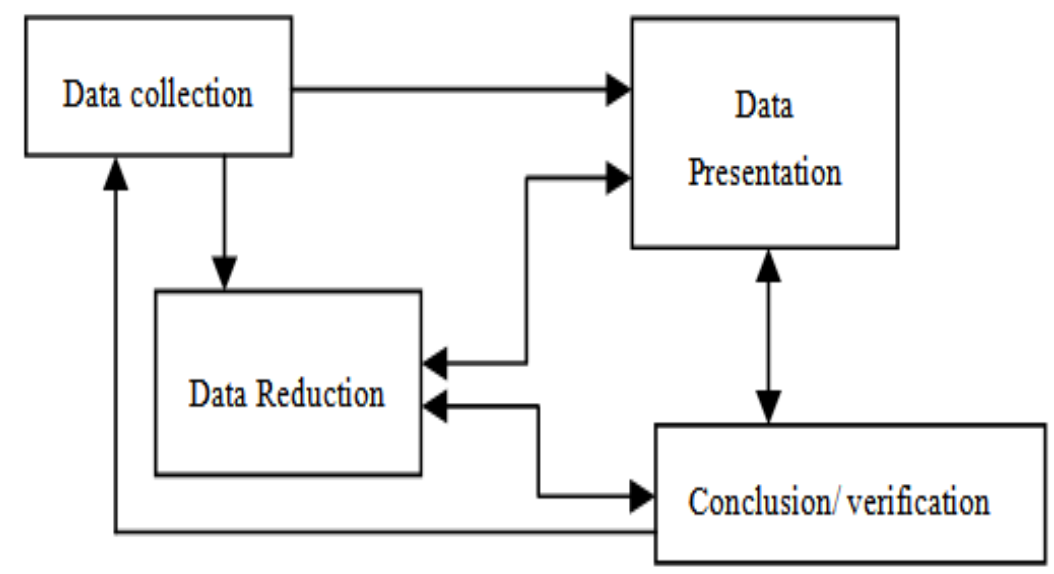

Source: modified from Miles and Huberman (1992)

Figure 1 Analysis Data Component (interactive model)

At this stage, we can see that before drawing a conclusion there are some steps that must be conducted to provide result of data presentation. Qualitative research is usually a conclusion that may answer the formulation of the problem formulated from the beginning, but may not also answer the formulation of the problem. The preliminary conclusion may be temporary because it can change when finding the next data collection so it can be credible if it is supported by proper and consistent evidence. The conclusion of the research taken from the results of reduction and data presentation is a 
tentative conclusion. This temporary conclusion can still change if other strong evidence is found during the data verification process in the field.

1. Data Validity Checking

a. In qualitative research it is necessary to have examination techniques to establish the validity of data. To obtain the validity of data, the researchers need required inspection techniques. The implementation of inspection techniques is based on a number of specific criteria. Test validity of data in this research is a test credibility of data (credibility) which includes extension of observation, and triangulation. Extension of observation is conducted by researchers to obtain information needed for the research. Meanwhile continuous observation by researchers is to obtain a lot of data in detail, complete and deep so that it will be easy to distinguish between useful and useless data.

b. Triangulation in testing the credibility of qualitative research is interpreted as checking data from various sources in various ways, and at various times. Triangulation used by researchers is triangulation technique and source triangulation. Triangulation technique is a technique to test the credibility by checking the data from the same source with different techniques of observation, interview, and documentation. Triangulation of resources is conducted by questioning different sources / informants. Researchers also hold a member check (agreement) to check the data obtained by researchers to all data given by respondents.

\section{Discussion and Result}

Information Technologies in supporting KAI must effectively become a bridge of relationships within the organizational structure so that the synergy between work in the organization and employees performance is created to achieve company goals. What KAI management has done to maximize the utilization of the information technology system is similar to the statement of Orgland \& Von Krogh (1998) which explains that changes in the company require three different forces to drive change: direction from 
top to bottom, horizontal process redesign and performance improvement from bottom up. Changes with performance improvements from the ground up often fail because they are not accompanied by clear directions from top to bottom. This has happened to revitalize the company from failing because executives are not able to move support and improvement ideas from frontline employees. Business process reengineering is often successful with a combination of horizontal process perspective and front-line engagement and is conducted with clear strategic direction from above and focus on critical processes that can create a company's competitive advantage.

Management Information System, Laudon (2011) explains that increasing efficiency in the business period that can increase profits will be known from the use of appropriate information systems and information technology. These are devices to create efficiency and productivity for service. However, rail operation and management in KAI have not used the most sophisticated information technology yet. The system still use the infrared technology which is a very supporting tool for more efficient railway operation. The role of information technology in supporting efficiency and productivity of train operation can be seen in the following figure:

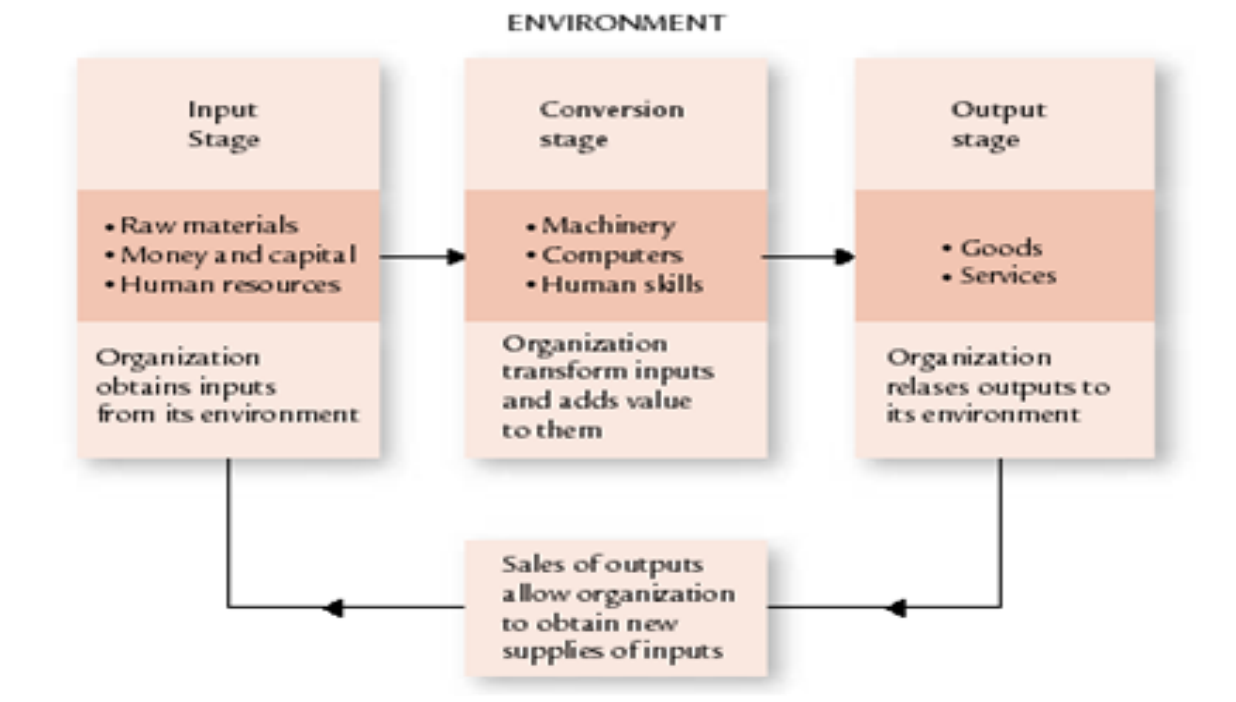

Figure 2 The linkage of information systems in encouraging the transformation of PT KAI 
Before the improvement of the company's information system, regular maintenance system in KAI and even KAI's rolling stock catalog did not exist. In 2003 KAI used SAP Material Management (MM). This module is a procurement and inventory tool used to manage the purchase, receipt, and storage of materials or parts and others. SAP MM with e-catalogs that can help to maximize inventory usage. This e-procurement process has helped companies to avoid problematic transactions and provide a good image for the company.

For Corporate Culture, there are five main things that must be upheld by all employees of PT KAI. They are as follows :

a. Integrity Act in accordance with the value of the organization and the code of ethics of the company. Employees have the understanding and desire to adapt to such policies and ethics and don't find difficult to do so.

b. Being professional means that employees have the ability and competency related to knowledge of work, such as master how to use and develop something, increase leadership knowledge related to the work with others.

c. Uncompromising and consistent safety in running or creating less work.

d. Being creative and innovative means that employees always create new ideas, develop sustainable improvement and create a conducive and positive environment which provides value added to stakeholders.

e. Giving Excellent Service means that employees provide the best service in accordance with satisfactory quality standards and expectations or exceed customer expectations by meeting the 6A main elements: Ability (Ability), Attitude, Appearance (Attention), Attention (Attention), Action (Action) and Accountability (Responsibility).

1. Strategy

In the era of business transformation, the transformation of PT KAI is achieved by changing goals, incentive systems, accountability, structure, power, system culture and corporate organization. In this case one of them can create a new strategy by doing reinventing, where the new strategy leads to restructure, have more profit, and become big. Through this 
reinventing strategy, it is expected that the company will become more competitive against superior competitor so that KAI can compete with similar company in local and international. Business is expected to grow and develop a varied economic network so that it will be stable and firm. Based on that reason PT Kereta Api Indonesia does the changes, as follows :

2. Restructuration

One of the strategic steps to improve the company's internal condition, performance of employees and increase the value of the company in PT $\mathrm{KAI}$ is by restructuring. The factors that trigger the restructuring are : Internal factors:

a. Vision and mission of the company

b. Financial condition and various inefficiencies that exist

c. Condition of facility and infrastructure that is relatively old

d. The quality of employees

e. Organizations that have not been able to accommodate all the main tasks and functions well.

External factors

a. Competition among transportation providers

b. Technology (information) is growing rapidly

c. The growing industrialization

d. A decline in funding capability by central government

e. A high population density and urban traffic tending to be more difficult to control

f. Various environmental issues and crisis of energy or natural resources becoming more serious and sensitive.

3. Synergy of Information Technology Development

The realization of service innovation undertaken by PT KAI is inseparable from the role of information technology. Information technology has become the basis of corporate work, culture and service development that has been going on for so long. In 2010, PT KAI synergized with PT Telkom in the development of information 
technology. Up to the present, the most prominent synergy is e-ticketing system. This system in fact manages to provide satisfaction with rail transport services. However, the synergy steps between PT KAI and PT Telkom do not only stop in the e-ticketing system. In 2014, the two StateOwned Enterprises (SOEs) are back to work together in the application of SAP system (system application and product), so that on January 1, 2014 the cooperation was expected to grow along between the two SOEs. In fact, PT Telkom is open to discuss various matters related to information technology of two state-owned synergies, not only for getting profit, but also for agents of change. PT KAI as a provider of rail services continues to improve services in Indonesian railways. The improvement of this service goes hand in hand with the transformation made by PT KAI. Transformation begins by changing the orientation of the original product from company oriented to be customer oriented. Therefore, various innovations were made so that the users of rail services feel the ease and benefits of services provided.

\section{Conclusion}

Transformation will continue because changes in information and technology will sustain to follow a technology that is popular at the time and to fulfil satisfaction by giving excellent service to users. In the future there are many challenges faced by PT KAI. There are some points that can be delivered:

1. Higher customer demands, requiring KAI always to improve service and innovation.

2. The development of industry and technology should also be anticipated in all systems implemented by KAI.

3. Internal improvement is still much to be done especially improvement and rejuvenation of facilities and infrastructure.

4. Integral inter systems should be developed and improved.

5. Integration can also be done with other transport mode operators. 
6. Focus on the main business of transport that is accompanied by the target revenue increase.

7. Economic growth that encourages logistic flow in various industries becomes a big opportunity for KAI to increase revenue from freight segment.

8. Improvement of facilities, infrastructure and service becomes the main factor considering consumer industry is very important and highly profitable.

9. Improvement of facilities and infrastructure is not fully controlled by $\mathrm{KAI}$, therefore it is necessary to increase synergies between the central government and local government, as well as with related parties.

10. The ideal form of synergy can also be done by imitating best practices from other countries, of course, adjusted to the conditions in Indonesia.

11. Strong leadership style has been proven to change KAI to be much better than previous conditions.

12. The target of increasing number of frequencies, increasing capacity, increasing number of lines and KAI routes will increase the number of users to be served by KAI.

\section{References}

Bell, S., and S. Morse. 2003. Measuring Sustainability. Learning from Doing. Earthscan. London.

Durugbo, C., Tiwari, A., \& Alcock, J. R. (2014). Managing integrated information flow for delivery reliability. Industrial Management \& Data Systems, 114(4), 628-651. https://doi.org/10.1108/IMDS-10-2013-0430

Ismiyati, Firdaus, M., \& Arubusman, D. A. (2016). Manajemen Pemeliharaan Bus Transjakarta Dalam Mencapai Standar Pelayanan Minimum, 3(2), 185-203.

Juliater Simarmata, Charles, \& Rizaldy, W. (2014). The Impact of Fuel Increase and Currency Exchange Depreciation on Indonesia Aviation Industry Sustainability. Jurnal Manajemen Transportasi \& Logistik (JMTransLog) 1(3), -, 199-208. https://doi.org///dx.doi.org/10.25292/j.mtl.v1i3.18

Kadarisman, M., Gunawan, A., \& Ismiyati, I. (2016). Kebijakan Manajemen Transportasi Darat dan Dampaknya Terhadap Perekonomian Masyarakat di Kota Depok. Jurnal Manajemen Transportasi \& Logistik, 3(1). Retrieved from http://www.ejournal.stmt- 
trisakti.ac.id/index.php/JMTRANSLOG/article/view/72

Koo, C., Chung, N., \& Kim, H.-W. (2015). Information Technology \& People Examining explorative and exploitative uses of smartphones: a user competence perspective Examining explorative and exploitative uses of smartphones: a user competence perspective. Information Technology \& People Information Technology \&amp; People Jinzhu Song Information Technology \&amp; People (Vol. 28). https://doi.org/10.1108/ITP-04-2013-0063

Ngee Goh, T. (2014). Professional preparation for service quality and organizational excellence. International Journal of Quality and Service Sciences, 6(2/3), 155. https://doi.org/10.1108/IJQSS-02-2014-0018

Ralph, J., Sipress, J. M., Reed, H. A., Moses, W. J., Ling, P. J., Lal, B. B., ... Ben- Zadok, E. (1995). Book reviews. Ethnic and Racial Studies, 18(3), 648-687. https://doi.org/10.1080/01419870.1995.9993883

Saribanon, E., Manajemen, S. T., Trisakti, T., Sitanggang, R., Manajemen, S. T., \& Trisakti, T. (2016). Kepuasan Pengguna Jasa Transportasi the Satisfaction of Transportation' S, 3(3), 317-326.

Satapathy, S. (2014). An analysis for service quality enhancement in

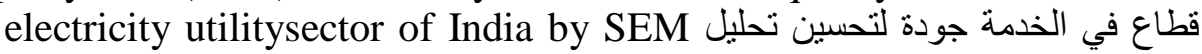
.الهيكلية المعادلة نمذجة طريق عن الهند في الكهرباء مرافق Benchmarking: An International Journal, 21(6), 964-986. https://doi.org/10.1108/BIJ-102012-0071

STMT Trisakti, H., Indah Susanthi STMT Trisakti, N., Setiawan STMT Trisakti, A., Indah Susanthi, N., \& Dian Octaviani, R. (2014). The Effect of Leadership Style on Motivation to Improve the Employee Performance. Jurnal Manajemen Transportasi \& Logistik, 1(3). Retrieved from http://ejournal.stmttrisakti.ac.id/index.php/jmtranslog/article/view/20/20

Tsai, C. L. (2014). The organizational climate and employees' job satisfaction in the terminal operation context of kaohsiung port. Asian Journal of Shipping and Logistics, 30(3), 373-392. https://doi.org/10.1016/j.ajs1.2014.12.007 